\title{
Titania nanomaterials produced from Ti-salt Flocculated Sludge in Water \\ Treatment
}

\author{
Jong-Ho Kim ${ }^{\mathrm{a}, \mathrm{b}^{*}}$, Dong Lyun Cho ${ }^{\mathrm{a}, \mathrm{b}}$, Geon-Joong Kim ${ }^{\mathrm{a}, \mathrm{c}}$, Baoyu Gao ${ }^{\mathrm{d}}$, Ho Kyong Shon ${ }^{\mathrm{a}, \mathrm{e}}$ \\ ${ }^{\mathrm{a}}$ Photo \& Environmental Technology Co. Ltd., Gwangju 500-460, Korea \\ bshool of Applied Chemical Engineering \& The Institute for Catalysis Research, Chonnam National University, \\ Gwangju 500-757, Korea \\ ${ }^{c}$ Department of Chemical Engineering, 253 Yonghyun-dong, Nam-gu, Inha University, Incheon, 402-751, Korea \\ ${ }^{d}$ School of Environmental Science and Engineering, Shandong University, No.27 Shanda South Road, Jinan 250100, \\ Shandong, People’s Republic of China \\ ${ }^{e}$ School of Civil and Environmental Engineering, University of Technology, Sydney (UTS), P.O. Box 123, Broadway, \\ NSW 2007, Australia \\ *Corresponding author: Fax number: +82-62-530-1889, E-mail address: jonghkim@jnu.ac.kr
}

\begin{abstract}
Titania is the most widely used metal oxide for the applications of pigments, paper, solar cells and environmental purification. In order to meet the demand of a large amount of titania, our group has developed a novel process which could significantly lower the cost of waste disposal in water treatment, protect the environment and public health and yield economically valuable titania. Titanium tetrachloride $\left(\mathrm{TiCl}_{4}\right)$ or titanium sulfate $\left(\mathrm{Ti}\left(\mathrm{SO}_{4}\right)_{2}\right)$ as an alternative coagulant in water treatment has been explored for the removal of various pollutants from contaminated water or wastewater. Flocculation efficiencies of the Ti-salts were superior to those of Al- and Fe- salts with additional benefits in that a large amount of titania can be produced by calcinating the flocculated floc. The produced titania showed high photocatalytic activity for the removal of volatile organic compounds. The large amount of titania can be applied to pigments, environment and construction materials which require a lot of titania usages. This review paper presents an historical progress from fundamental to application in terms of the detailed
\end{abstract}


production process, characterization, photoactivity of titania produced from Ti-salt flocculated sludge, and its various applications.

Keywords: Flocculation; Nanomaterial; Photocatalysis; Sludge; Titania; Titanium salt; Water treatment

\section{Abbreviations}

AW: Artificial wastewater

BTSE: Biologically treated sewage effluent

DOC: Dissolved organic carbon

EC50: Effective concentration of a 50\% loss of bioluminescence obtained after 15 min exposure

LC: Lethal concentration

SEM/EDX: Scanning electron

microscopy/energy dispersive X-ray

SW: Sea water

XRD: X-ray diffraction
BET: Brunauer, Emmett and Teller

COD: Chemical oxygen demand

DW: Drinking water

HRTEM: High-resolution transmission electron

microscopy

UV: Ultraviolet

USEPA: United States Environmental Protection

Agency

WW: Wastewater

\section{Introduction}

\subsection{Flocculation in water and wastewater treatment}


Systematic treatment of wastewater for the prevention of pollution and diseases in urban society commenced in the late $19^{\text {th }}$ and early $20^{\text {th }}$ centuries. During the last century, wastewater treatment was continually refined to improve its performance and meet stringent disposal standards. These treatment processes use a range of physical, chemical and biological methods. Chemical treatment involves the removal or conversion of contaminants by the addition of particular chemicals or by other chemical reactions. Flocculation has been used for over 100 years to treat drinking water as well as sewage, stormwater, seawater and other industrial wastewater streams.

Flocculation causes the coagulation or agglomeration of contaminant particles in large flocs to easily settle down [1]. Flocculation can also be used for the removal of organic matter, which generates the formation of trihalomethane during disinfection. Commonly-used coagulants include aluminium sulfate, iron salts, and polyaluminum chlorides [2]. However, two major problems are involved in the flocculation process. The first one is toxicity of the coagulant. Stauber et al. [3] have reported that public worries on the connection of the residual aluminium coagulant with Alzheimer's disease were ever increasing. To resolve this problem, Al-based coagulants are avoided in water treatment plants. The second one is production of solid waste after flocculation. The flocculation process using $\mathrm{Al}-$ and Fe-salt coagulants produces a large amount of sludge. Most of the sludge is solid waste from which nothing can be recovered or reused, and thus requires further treatment such as incineration, landfill, etc. This makes the process to be an inefficient way for the wastewater treatment. Therefore, a novel coagulant that can reduce the amount of sludge or produce reusable material is required to make the process efficient by offering environmental and economical benefits associated with sludge handling.

\subsection{Titania}


Table 1 shows the history of titania from its discovery to application. Titania is the most widely used metal oxide that is used for pigments, paper, solar cells and environmental applications for the degradation of waste and for hydrogen generation by photocatalytic water-splitting. Such a wide range of applications of titania implies that the demand of titania would greatly be increased. For example, titania is produced by about 6 million ton/year and $10 \%$ per year is growing in Asia. Dupont, Cristal, Tronox, Huntsman, Kronos, Ishihara Sangyo, Kemira and Sachtleben companies are the major manufacturers. Anatase titania is mainly used for plastic resin, water paint, rubber, paper, textile, while rutile is utilized for oil paint and resin. Ultrafine titania is useful for cosmetics, UV protection film and titania with high purity is applied to electrical materials such as sensors and thin film. Titania used for industrial applications is produced by various methods namely sulfate, chloride (vapor method), alkoxide, and specific methods [4,5]. Among the various methods, the chloride method is widely employed by more than 50\%. However, these processes discharge a large amount of wastewater which contains strong acid and chloride/sulfate ions at high concentrations. This results in the difficulty of wastewater treatment. 
Table 1 History of titania from discovery to application

\begin{tabular}{|c|c|}
\hline Year & Remarks \\
\hline 1791 & - Discovery of the titanium element by William Gregor in UK \\
\hline 1800’s & - Fundamental chemical reactions of titanium \\
\hline 1821 & - Discovery of titania \\
\hline 1916 & - Commercial preparation of titania for white pigment by a sulfate method in Norway \\
\hline 1972 & $\begin{array}{l}\text { - Honda-Fujishima effect (photocatalytic reaction): photooxidation in titania was used to chemically split } \\
\text { water over titania to form } \mathrm{H}_{2} \text { and } \mathrm{O}_{2} \text {. }\end{array}$ \\
\hline 1980 & - Photocatalysis on titania and Pt/titania powder (short circuit photoelectron chemical cell) \\
\hline 1985 & $\begin{array}{l}\text { - Photocatalysis on highly dispersed titania anchored on various supports } \\
\text { - Photocatalysis in the zeolite (cavities and frameworks) }\end{array}$ \\
\hline 1987 & $\begin{array}{l}\text { - Ti/Si, Ti/Al binary oxide photocatalysts } \\
\text { - Size quantization effect on the photocatalysis of titania } \\
\text { - Nanoscale titania particles }\end{array}$ \\
\hline 1990 & - Titania coating on ceramic surface \\
\hline 1991 & $\begin{array}{l}\text { - Idea of sensitized photocatalysis (Grätzel solar cell) } \\
\text { - Purification and detoxification of polluted water }\end{array}$ \\
\hline 1993 & - Applications of titania photocatalysis to polluted water and air purification \\
\hline 1996 & - Inactivation of pathogenic microorganism in air and water \\
\hline 1997 & - New function of titania thin film photocatalyst (superhydrophilic phenomena) \\
\hline 1998 & $\begin{array}{l}\text { - Second generation titania in powder and thin film forms (ion-implantation and RF magnetron sputtering } \\
\text { method) }\end{array}$ \\
\hline 2000 & - Applications of titania photocatalysts on a global scale \\
\hline 2001 & - Photocatalytic water splitting under visible light irradiation \\
\hline 2007 & - A novel method to prepare titania from Ti-salt flocculated sludge \\
\hline
\end{tabular}

To solve the above-mentioned problems in the sections 1.1 and 1.2 (sludge reduction and titania production), a new process by which economically valuable titania can be recovered from wastewater has been developed and explored by our group [4-21]. A large amount of functional titania was produced from wastewater sludge generated by the Ti-salt flocculation. In addition, the novel flocculation process simultaneously reduced the problem of strong acid and high concentrations of chloride ions using a small amount of Ti-salt as a coagulant to treat a large volume of wastewater. This review thus aims to introduce the novel process to produce titania from Ti-salt flocculated sludge for the past, present and future experience. Here, we mainly focus on understanding of photocatalyst in preparation, charactertization and application rather than water 
treatment. However, the detailed understanding of water treatment aspects can be found in the references used in this article [4-21].

\section{Ti-salt coagulant in water treatment}

The possibility using titanium compounds as a coagulant in water treatment was first investigated by Upton and Buswell in 1937 [22]. They found that titanium sulfate $\left(\mathrm{Ti}\left(\mathrm{SO}_{4}\right)_{2}\right)$ was better in removing fluoride due to a quadrivalent cation instead of the trivalent aluminium or iron ions which are mostly used in water treatment. They added that ilmenite extract gave much better coagulation in the colored water than aluminium or ferric sulfates. Furthermore, titanium salts appeared feasible from the standpoint of cost and the $\mathrm{pH}$ range for good floc formation. The titanium floc was formed more rapidly in a bulkier condition. On the other hand, titanium sulfate showed no advantage over aluminium sulfate in fluoride removal but removed color from water more efficiently. Lokshin and Belikov [23] also investigated Ti-salt flocculation. Wastewater can be efficiently purified to remove fluoride ions with titanium (IV) compounds, especially with hydrated oxotitanium sulfate with [F'] concentration achieved of $0.5-0.6 \mathrm{mg} / \mathrm{l}$. They found that the concentration of the sulfate ions in purified water after titanium sulfate flocculation did not exceed the permissible limit at the optimum doses of wastewater purification.

The effectiveness of Ti-salts has been performed in terms of removal of organic matter, turbidity, nutrients and floc properties. Shon et al. [5] recently proposed a novel process to utilize the Ti-salt coagulant to recover a useful byproduct. Removal of organic matter of different molecular sizes by Ti-salt flocculation was similar to that of the most widely-used Fe- and Al-salt flocculation. The removals of organic matter at optimum doses by $\mathrm{Fe}, \mathrm{Al}$ and Ti-salt flocculation were 73\% (13.8 Femg/L), 70\% (16 Al-mg/L) and 70\% (9.8 Ti-mg/L), respectively. The mean size of Ti-, Fe- and Al- 
salt flocs was $47.5 \mu \mathrm{m}, 42.5 \mu \mathrm{m}$ and $16.9 \mu \mathrm{m}$, respectively. The settleability of flocs by Ti-salt coagulant was better than that by $\mathrm{FeCl}_{3}$ coagulant and $\mathrm{Al}_{2}\left(\mathrm{SO}_{4}\right)_{3}$.

The flocculation with $\mathrm{TiCl}_{4}$ and $\mathrm{Ti}\left(\mathrm{SO}_{4}\right)_{2}$ using synthetic wastewater in terms of turbidity, DOC, UV absorbance at $254 \mathrm{~nm}\left(\mathrm{UVA}_{254}\right)$ and colour [11]. The wastewater with Ti-salt coagulants was stirred rapidly for 1 minute at $100 \mathrm{rpm}$, followed by 20 minutes of slow mixing at $30 \mathrm{rpm}$, and 30 minutes of settling. The Ti-salts used were compared with $\mathrm{FeCl}_{3}$ and $\mathrm{Al}_{2}\left(\mathrm{SO}_{4}\right)_{3}$. $\mathrm{TiCl}_{4}$ showed better turbidity removal, while $\mathrm{Ti}\left(\mathrm{SO}_{4}\right)_{2}$ showed the highest reduction of UV absorbance and colour at all the ranges of $\mathrm{pH}$. Compared to aluminum and iron salt coagulants, $\mathrm{TiCl}_{4}$ and $\mathrm{Ti}\left(\mathrm{SO}_{4}\right)_{2}$ were found to have similar organic removal up to $60-67 \%$ and similar molecular weight removal of organic matter (Figure 2). The decantability of the settled flocs was higher for $\mathrm{TiCl}_{4}, \mathrm{Ti}\left(\mathrm{SO}_{4}\right)_{2}$ and $\mathrm{FeCl}_{3}$ compared with $\mathrm{Al}_{2}\left(\mathrm{SO}_{4}\right)_{3}$. It can be concluded that Ti-salt coagulants have a high potential to apply for water treatment plants. Kim et al. [15] also studied the flocculation of dye wastewater using $\mathrm{TiCl}_{4}$ and ferric sulfate $\left(\mathrm{FeSO}_{4}\right)$. The results showed that $77.6 \%$ of chemical oxygen demand $\left(\mathrm{COD}_{\mathrm{Mn}}\right)$ was removed from dye wastewater when using $\mathrm{FeSO}_{4}$ as coagulant, while $\mathrm{TiCl}_{4}$ removed $75.9 \%$ of $\mathrm{COD}_{\mathrm{Mn}}$. On the other hand, the precipitation efficiency was better for $\mathrm{TiCl}_{4} \mathrm{Compared}$ with $\mathrm{FeSO}_{4}$.
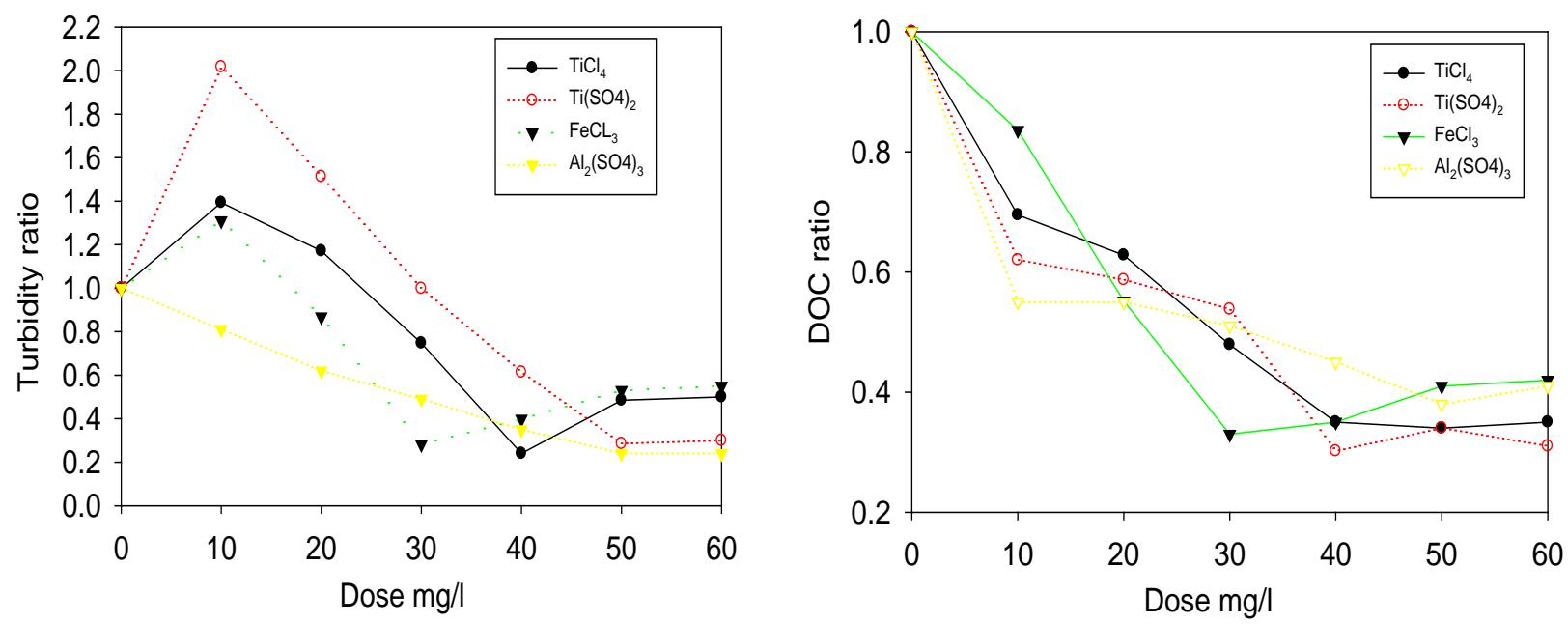
Figure 2 Variation in residual turbidity ratio and residual dissolved organic carbon (DOC) ratio as a function of coagulant doses

\section{Preparation and characterization of titania produced from Ti-salt flocculated sludge}

The settled flocs (sludge) produced after $\mathrm{TiCl}_{4}$ flocculation were recycled with a novel process, which has a significant potential to the lower cost of waste disposal, protect the environment and public health and yield economically useful by-products [9]. Figure 3 shows X-ray diffraction patterns to identify the particle after calcination of the settled floc at different temperatures from 100 to $1000^{\circ} \mathrm{C}$. The anatase pattern was found above $600^{\circ} \mathrm{C}$. At lower temperature, the remaining organic matter interfered titania crystallization. On the other hand, at $1000^{\circ} \mathrm{C}$, the anatase phase changed to rutile. Although there are a lot of different compounds in synthetic wastewater, genuine titania crystalline structure was found. The titania produced in such a way is efficient and economical not only in terms of removal of organic matter in wastewater, but also in sludge reduction. As the titania can be produced in significant quantities in wastewater treatment plants, they can also easily meet demands for titania in other applications.

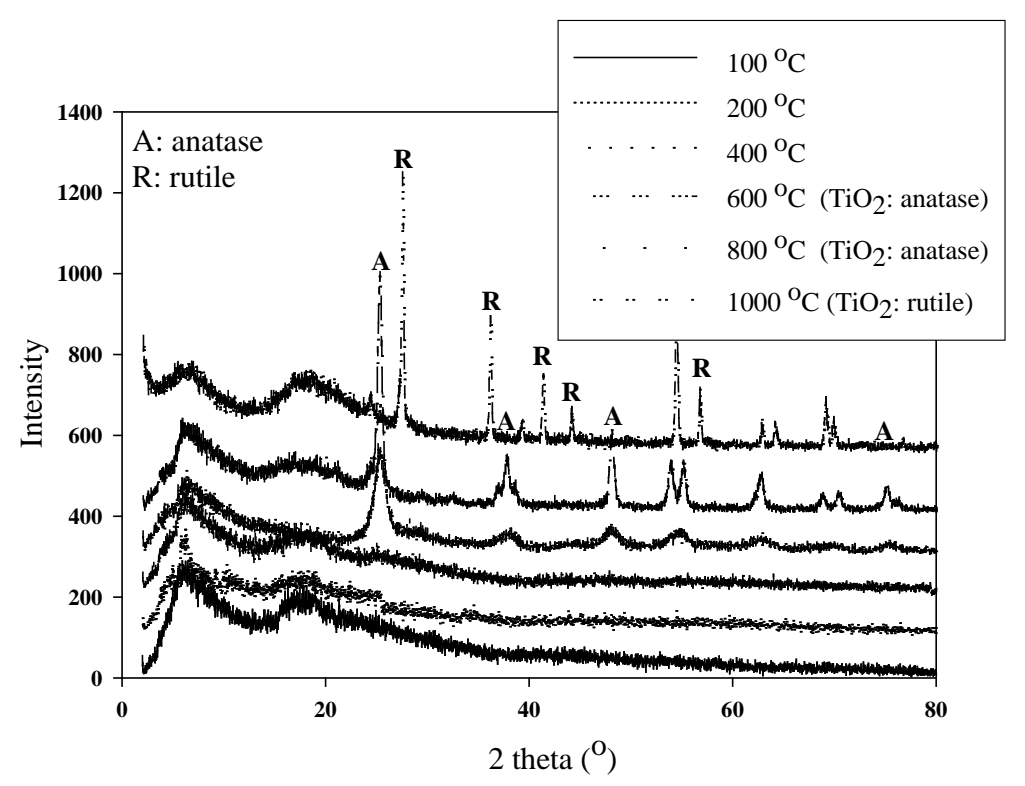


Figure 3 XRD images of the settled floc after $\mathrm{TiCl}_{4}$ flocculation at different temperatures

The primary crystallite size of the titania produced from sludge after calcination of $600^{\circ} \mathrm{C}$ with synthetic wastewater was about $6.0 \mathrm{~nm}$ (Figure 4). On the other hand, the size of titania at $1000^{\circ} \mathrm{C}$ calcination increased up to $50 \mathrm{~nm}$. The specific surface area of the functional titania at $600^{\circ} \mathrm{C}$, $800^{\circ} \mathrm{C}$ and $1000^{\circ} \mathrm{C}$ was $76.3 \mathrm{~m}^{2} / \mathrm{g}, 5.96 \mathrm{~m}^{2} / \mathrm{g}$ and $0.74 \mathrm{~m}^{2} / \mathrm{g}$, respectively. Based on the scanning electron microscopy/energy dispersive X-ray (SEM/EDX) results, $\mathrm{C}$ and $\mathrm{P}$ atoms were found to be mainly doped in/on titania. The carbon compounds may be due to the remaining carbon from the settled organic floc, which was not volatile to carbon dioxide and water. The averaged elemental content at $100^{\circ} \mathrm{C}, 200^{\circ} \mathrm{C}, 400^{\circ} \mathrm{C}, 600^{\circ} \mathrm{C}, 800^{\circ} \mathrm{C}$ and $1000^{\circ} \mathrm{C}$ in terms of Ti:O:C:P was 10.0:59.4:28.9:1.8, 11.2:61.4:26.0:1.36, 13.0:61.9:2.0:2.1, 13.2:64.6:19.8:2.4, 17.0:68.5:12.1:2.4 and 17.7:70.7:10.4:1.2, respectively. Here, $9.8 \mathrm{mg}$ of Ti concentration was dosed and $17.86 \mathrm{mg}$ of titania was experimentally recovered. Thus, the impurity was $1.78 \mathrm{mg}$ in particles used in this study. The percentage of the impurity was $9.97 \%$.

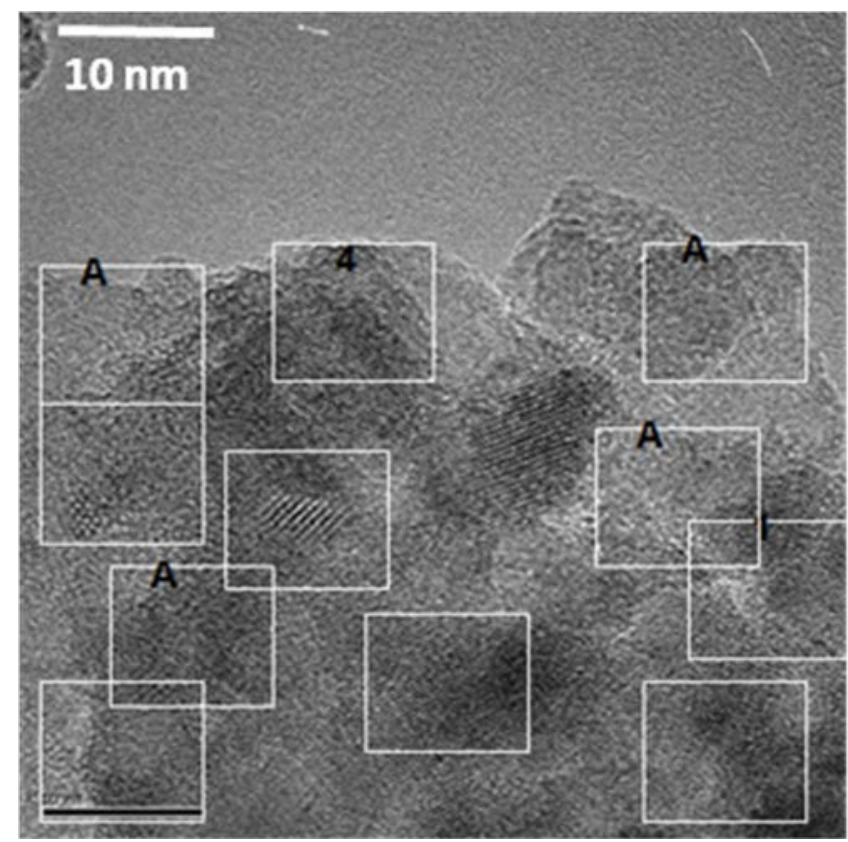

a)

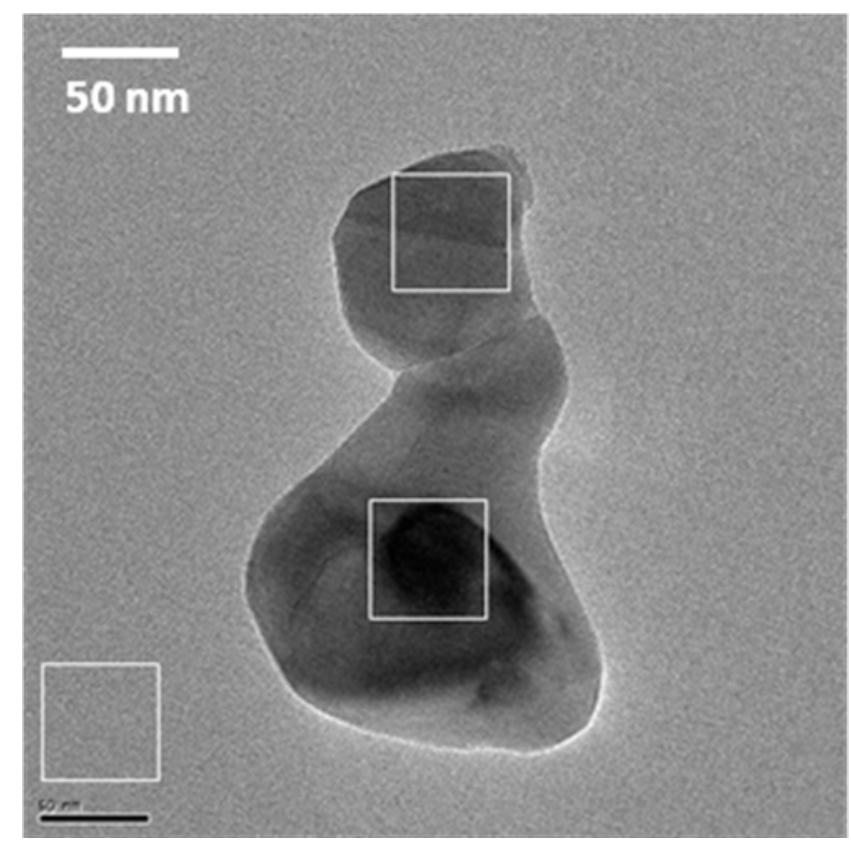

b)

Figure 4 High resolution transmission electron microscope image of titania produced from sludge with Ti-salt flocculation (a) $600^{\circ} \mathrm{C}$ and b) $1000^{\circ} \mathrm{C}$ ) 
The photocatalytic activity test with P-25 (commercially available photocatalyst) and the titania produced from the Ti-salt sludge $\left(600^{\circ} \mathrm{C}, 800^{\circ} \mathrm{C}\right.$ and $1000^{\circ} \mathrm{C}$ calcination) was investigated under irradiation of UV (Sankyo, F10T8BLB, three 10W lamps) using the method of photodecomposition of gaseous acetaldehyde (Figure 5). The detailed experimental conditions can be found elsewhere [5]. As the BET surface area of titania after $600^{\circ} \mathrm{C}\left(76.3 \mathrm{~m}^{2} / \mathrm{g}\right), 800^{\circ} \mathrm{C}\left(5.96 \mathrm{~m}^{2} / \mathrm{g}\right)$ and $1000^{\circ} \mathrm{C}(0.74$ $\mathrm{m}^{2} / \mathrm{g}$ ) was very different, the amount of titania used in the experiments was varied to achieve a constant amount of removal (20\%) of acetaldehyde during titania adsorption following which it was irradiated with UV light. The concentration of acetaldehyde was measured by gas chromatography (Youngin, M600D). Photocatalytic removal of acetaldehyde with titania after $600{ }^{\circ} \mathrm{C}$ calcination was higher than that with P-25 under UV irradiation. On the other hand, the photocatalytic removal with titania after $800{ }^{\circ} \mathrm{C}$ and $1000{ }^{\circ} \mathrm{C}$ was lower than that with P-25. Although this figure is not shown, the removal of acetaldehyde was small with all titania under visible light.

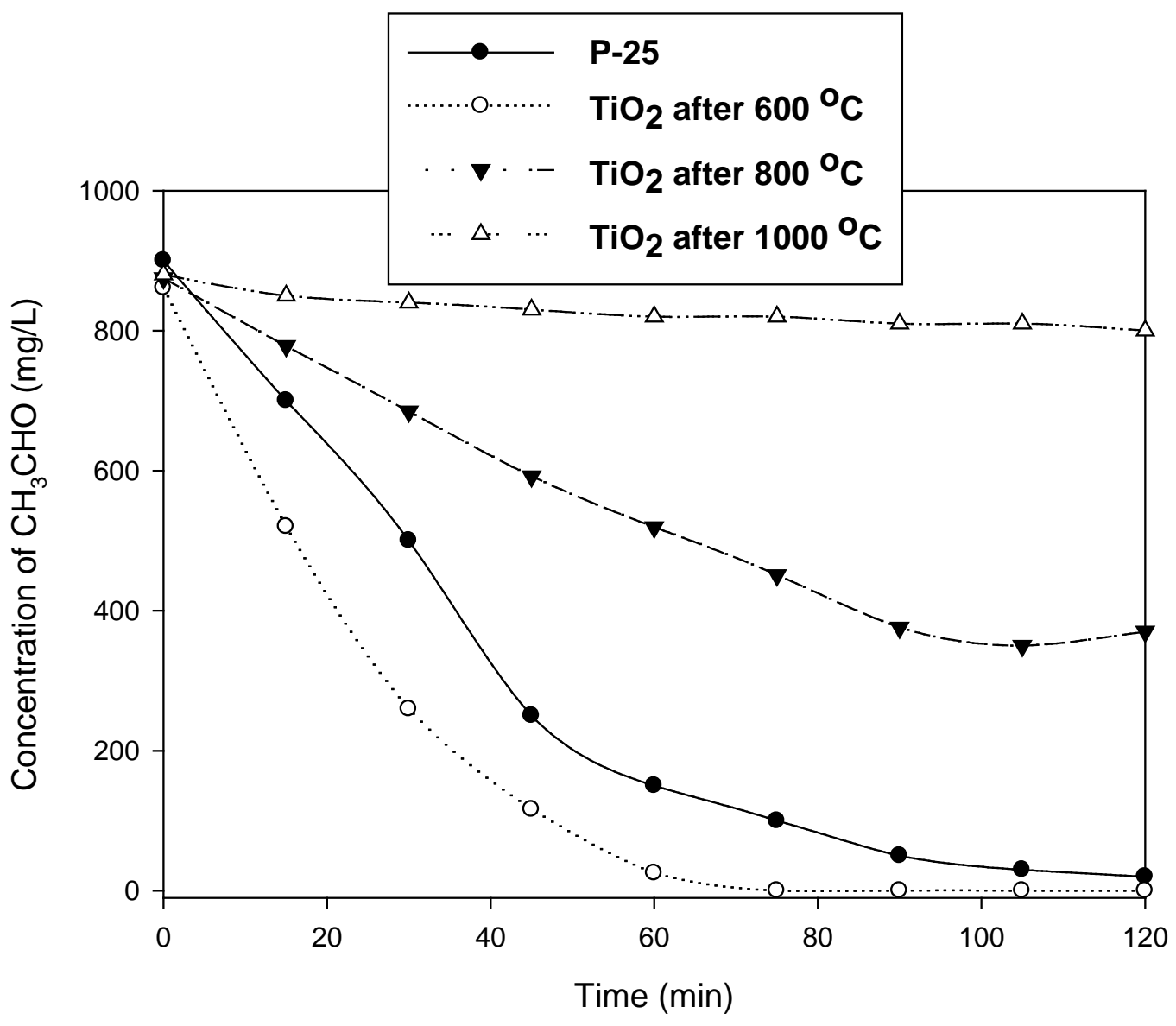


Figure 5 Variation of acetaldehyde concentration with irradiation time (initial concentration $=1000$ mg/L; UV irradiation = black light three $10 \mathrm{~W}$ lamps)

In order to investigate a real application of Ti-salt flocculation with drinking water (DW), wastewater (WW) from biologically treated sewage effluent, and seawater (SW), the characteristics of titania produced from sludge of Ti-salt flocculation were studied by Okour et al. [10]. The XRD patterns from DW, WW and SW showed that the anatase structure was also predominant from different water sources. The crystallite size of titania from DW, WW, SW and titania-P25 was 13, 15, 40, and $25 \mathrm{~nm}$, respectively [6]. The difference in crystallite size among different water sources was probably due to impurities in the flocculated sludge after Ti-salt flocculation and calcination. The BET surface area of titania nanoparticles from DW, WW, SW and titania-P25 was 90.2, 103.5, 68.1 and $42.3 \mathrm{~m}^{2} / \mathrm{g}$, respectively. This can be concluded that titania produced from Ti-salt flocculated sludge can be made with different water resources.

Due to the titania production from different water sources present in many different organic/inorganic compounds, it is essential to investigate the washing effect of titania produced from sludge. El Saliby et al. [12] examined the effect of washing on titania produced from sludge of Ti-salt flocculation with synthetic wastewater. The titania produced was washed using $\mathrm{HCl}, \mathrm{NaOH}$ and pure water to determine the effect of washings on adsorption and photocatalytic oxidation of acetaldehyde. The extent of photooxidation of synthetic wastewater by the produced titania after different washings showed several benefits. Washed titania improved the adsorption and the photocatalytic ability in decomposing acetaldehyde under UV-irradiation. Titania after alkali washing was fast in decomposing organic compounds in water phase. Similarly, titania after acidic washing was better than as-prepared titania.

The mechanism of titania production from sludge after Ti-salt flocculation has not explained 
because flocculation is a complex phenomenon. However, it can be generally explained as follows. As coagulant, $\mathrm{TiCl}_{4}$ changes into $\mathrm{TiOCl}_{2}$ when it is placed in aqueous phase. Depending on the $\mathrm{pH}$ of the system, the $\mathrm{TiOCl}_{2}$ hydrolyses to $\mathrm{Ti}(\mathrm{OH})_{4}$. The negatively-charged organic matter is absorbed by $\mathrm{Ti}(\mathrm{OH})_{4}$ and organic matter is agglomerated with the $\mathrm{Ti}(\mathrm{OH})_{4}$ into large flocs. During calcination of the settled floc, $55 \%$ of water and $20 \%$ of organic matter in the wastewater are vaporized and result in a compound of $\mathrm{TiO}_{1.42} \mathrm{C}_{0.44} \mathrm{P}_{0.14}$.

\section{Aquatic toxicity evaluation of titania nanoparticles produced from sludge of $\mathrm{TiCl}_{4}$ flocculation of wastewater and seawater}

Flocculation using Ti salt is efficient and economical because the flocculated sludge can be recycled to produce a valuable byproduct of titania nanoparticles. However, the toxicity of Ti-salt is not known to be safely used in water treatment. Thus the aquatic toxicity of the $\mathrm{TiCl}_{4}$ flocculation processes was investigated to assess the environmental safety [6]. D. magna and $V$. fischeri bioassays were carried out to analyze the toxicities of supernatant after $\mathrm{TiCl}_{4}$ flocculation and recycled titania nanoparticles from the sludge.

Figure 6 shows the dose-response curves of $\mathrm{TiCl}_{4}$ coagulant and the threshold concentration values (EC50) of titania in terms of light emission of $V$. fischeri exhibited by the whole effluent toxicity test (15 min exposure) with artificial wastewater (AW), biologically treated sewage effluent (BTSE) and seawater (SW). Here the EC50 values are a 50\% loss of bioluminescence obtained after 15 min exposure. The results are based on the whole effluent toxicity test (15 min exposure). Light emission rapidly decreased with the increase of $\mathrm{TiCl}_{4}$ concentration. The inhibition percentages at 62.5 and $1,000 \mathrm{mg} / \mathrm{L}$ of $\mathrm{TiCl}_{4}$ concentration were $5.8 \%$ and $72.3 \%$, respectively. Based on USEPA probit analysis program, the inhibition of bioluminescence of $V$. fischeri (EC50) was at $739.3 \mathrm{mg} / \mathrm{L}$ of $\mathrm{TiCl}_{4}$ concentration. The threshold of titania concentration values (EC50) was also investigated 
after 15 min exposure. For the titania produced from SW, the EC50 value was not found. The maximum loss of bioluminescence was $14 \%$. However, the EC50 values of titania produced from AW, BTSE, and P-25 were 650.6, 940.6, and $830.8 \mathrm{mg} / \mathrm{L}$, respectively. The relatively high EC50 indicates that there is no significant toxic effect on titania.

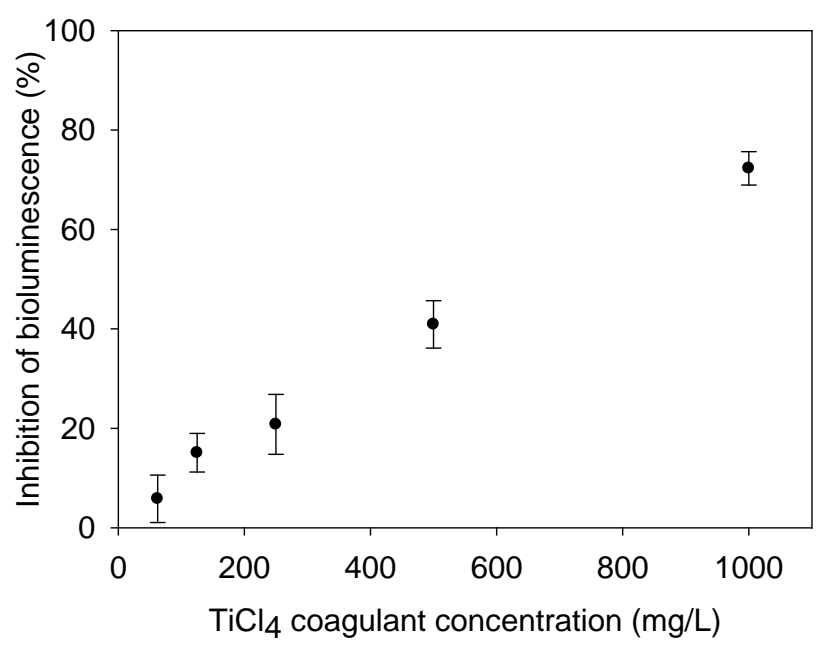

(a)

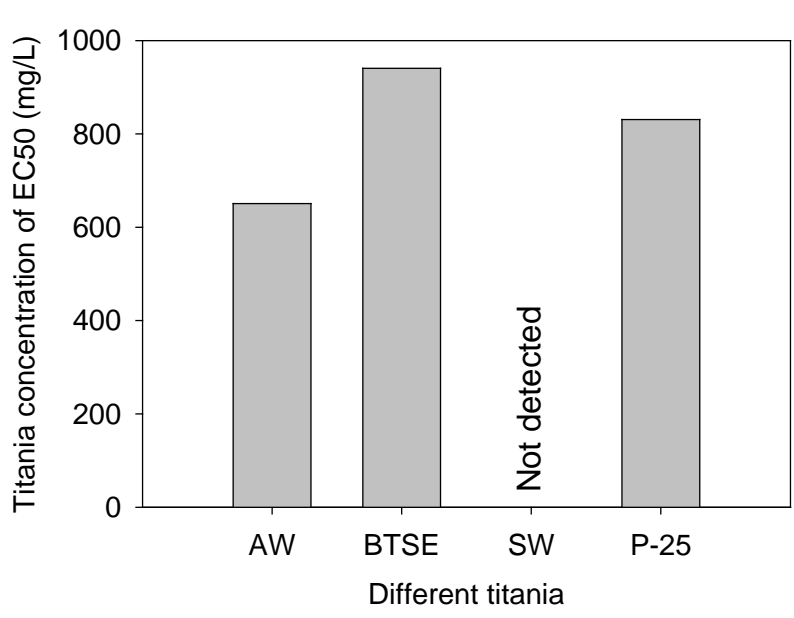

(b)

Figure 6 (a) Dose-response curves of $\mathrm{TiCl}_{4}$ coagulant and (b) threshold concentration values (EC50) of titania in terms of light emission of $V$. fischeri exhibited by the whole effluent toxicity test (15 min exposure)

The aquatic toxicity, D. magna mortality, of titania produced from different water sources was also investigated. Titania concentration was varied from $0 \mathrm{mg} / \mathrm{L}$ to $200 \mathrm{mg} / \mathrm{L}$. The maximum mortality of titania produced from AW, BTSE and SW was less than 15\%, while that of titania-P25 was 25\% at the concentration of $100 \mathrm{mg} / \mathrm{L}$. As all the titania particles indicated low mortality, the LC50 was not found. Therefore, LC5, LC10 and LC15 were compared using USEPA probit analysis program. The commercially available P-25 titania showed lower values of LC5 (5.9 mg/L), LC10 (28.4 mg/L) and LC15 (81.3 mg/L) compared to titania produced from AW, BTSE and SW. This result clearly indicates that titania nanoparticles produced from AW, BTSE and SW have low acute toxicity in aqueous condition. 


\section{Pilot/full-scale Ti-salt flocculation to produce titania with dye wastewater}

A verification of pilot-scale Ti-salt flocculation requires investigating and improving process performance in realistic operational conditions. Kim et al. [15,21] carried out the pilot-scale process to demonstrate feasibility of this process. The pilot processes consisted of equalization, rapid mixing, slow mixing and sedimentation tanks and treated $1 \mathrm{~m}^{3} / \mathrm{h}$ of dye wastewater. During the rapid mixing time, the $\mathrm{pH}$ was adjusted and the Ti-salt coagulant was added at $100 \mathrm{rpm}$. After flocculation, the settled floc was collected from the sedimentation tank and then the floc went through a filter press to dewater the floc. The capacity of the filter press used in this study was 1.2 $\mathrm{m}^{3} / \mathrm{h}$. The dewatered sludge was dried in rotary furnace at $300^{\circ} \mathrm{C}$. The dry sludge was then calcined at $600^{\circ} \mathrm{C}$ to remove organic content of the sludge.

XRD patterns were first measured to identify the structure of calcined Ti-salt flocculated sludge with dye wastewater. The anatase phase was predominant. The BET specific surface areas of titania were $71 \mathrm{~m}^{2} / \mathrm{g}$, which was higher than that of the P-25 titania $\left(50 \mathrm{~m}^{2} / \mathrm{g}\right)$. Figure 7 shows the SEM and HRTEM images of titania. The SEM images showed different sizes, shapes and dimensions of the aggregated particles. The HRTEM images showed that nanoparticles of about $20 \mathrm{~nm}$ size were formed after calcination at $600^{\circ} \mathrm{C}$. Titania calcined at $600{ }^{\circ} \mathrm{C}$ produced a high proportion of up to $25 \%$ of $10-25 \mathrm{~nm}$ size particles. EDX analysis was performed to determine the presence of the different elements in titania. Titania was mainly doped with C, Si and Na atoms, whereas P-25 was high purity, consisting of only $\mathrm{Ti}$ and $\mathrm{O}$ atoms. The atomic percentages of $\mathrm{C}$, Si and $\mathrm{Na}$ in titania were $5.1 \%$ and $1.1 \%$ and $0.6 \%$, respectively. 


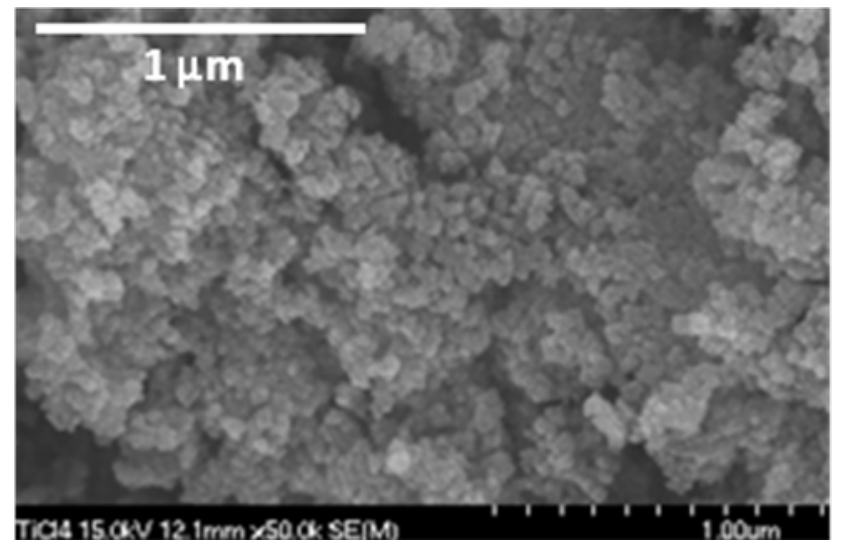

(a)

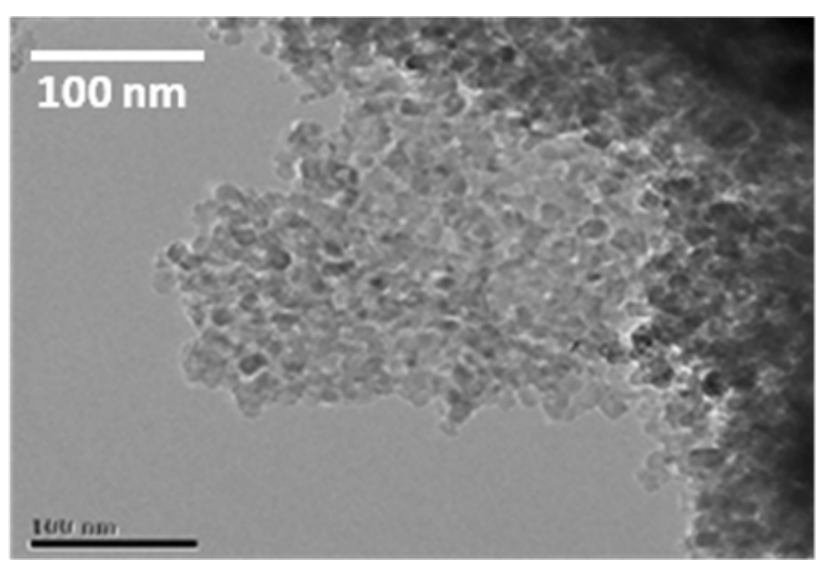

(b)

Figure 7 (a) SEM and (b) HRTEM images of titania produced from sludge with dye wastewater

The photocatalytic oxidation of acetaldehyde was investigated with titania produced from Ti-salt flocculated sludge with dye wastewater. Acetaldehyde was adsorbed onto titania surface under dark conditions for 60 minutes (UV lamp off). The acetaldehyde removal after 60 minutes adsorption was trivial for all titania samples used. However, the complete removal of acetaldehyde was observed within 80 min under UV irradiation. Similar removal compared to that with P-25 was observed.

\section{Application of titania produced from Ti-salt flocculated sludge}

Since the titania is produced from sludge, it contains some impurities. This implies that the titania produced from sludge is not suitable for the application of pure titania. In addition, a large amount of titania can be produced in a water treatment plant. For example, a medium size (85000 $\left.\mathrm{m}^{3} / \mathrm{d}\right)$ dye wastewater treatment plant could produce 16,000 kg/day of titania. Figure 8 shows the schematic diagram of titania production in terms of mass balance after sludge dewatering, dry and calcination. $7 \%$ of wastewater sludge mass can be made into valuable titania nanoparticles. The application of the large amount of titania needs to require a lot of titania usages. Thus, the potential applications of titania produced from Ti-salt flocculated sludge with polluted water are possibly a pigment, 
environment, construction material and energy industry.

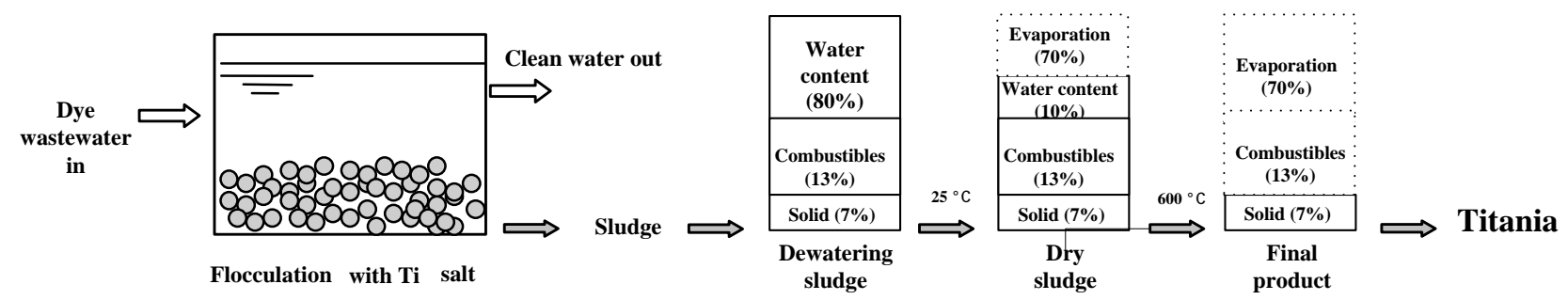

Figure 8 Schematic diagram of titania production in terms of mass balance after sludge dewatering, dry and calcination

\subsection{Use to titania photocatalyst}

As a photocatalyst for environmental applications, titania produced from Ti-salt flocculated sludge can be used to purify contaminated water, air, soil and waste. Photocatalysis is by far one of the most superior technologies in the environmental purification because unlike many other technologies, photocatalysis does not serve as a mere phase transfer but completely degrades various harmful organic pollutants by converting to innocuous substances such as $\mathrm{CO}_{2}$ and $\mathrm{H}_{2} \mathrm{O}$.

Titania coupled with UV light oxidizes organic pollutants into nontoxic materials and disinfects certain bacteria in water. This technology is very effective in removing further hazardous organic compounds and at killing a variety of bacteria and some viruses in the secondary wastewater treatment. Heterogeneous photocatalysis is an alternative treatment method for decontamination of organic compounds and disinfection of microorganisms to purify potable water.

One of the other applications of titania produced from sludge is the remediation of organically polluted soil or sludge. Higrashi and Jardim [24] used heterogeneous titania to degrade pesticide (diuron) to evaluate the potential use of this technology for in situ remediation. They reported that the photocatalytic treatment combined with solar light to be very efficient in the destruction of 
diuron in the top $4 \mathrm{~cm}$ of contaminated soil, with the degradation rate markedly dependent on the irradiation intensity. Oil spills in the sea and ocean is one of the major environmental disasters in marine environment. Researches have been trying to study the effect of photodegradation in cleaning up the marine environment. The application of titania photocatalysis has therefore been reported for the remediation of marine environment [25-27].

Figure 9 shows applications of titania produced from sludge to titania coating materials, titania ceramic filter for air/water purification, titania coated concrete brick and pavement brick. Among the applications, titania from sludge has high application potential in the construction industry. Photocatalytic ceramics, self cleaning glass and photocatalytic cements can be mixed with titania. Organic dust that may come in contact with the surface is removed by photocatalytic reaction in presence of sun light. This technology allows the creation of many exterior and interior facades and self-cleansing rooftops from ceramic and glass tiles. More applications could be found for building applications such as self cleansing pavements, walls, tunnels, curbs, and so on to remove $\mathrm{NO}_{\mathrm{x}}$ and $\mathrm{SO}_{\mathrm{x}}$ from the air produced by vehicular emissions. Photocatalyst-modified cements are used for various applications in buildings, self-cleaning surfaces and solar-powered remediation devices for polluted waters [28].

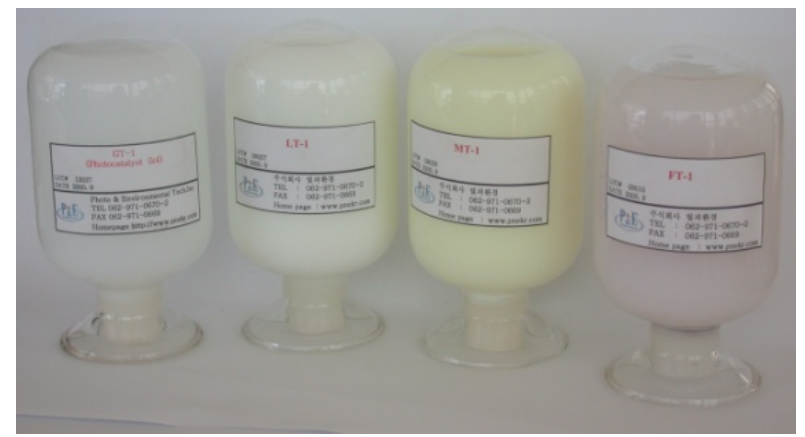

(a)

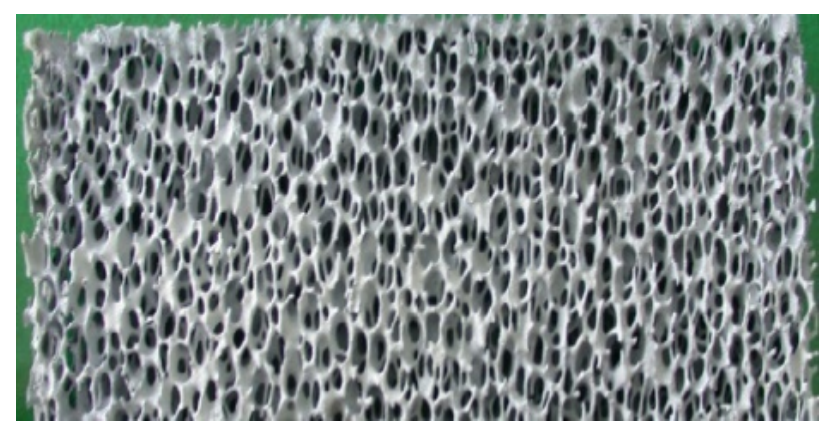

(b) 


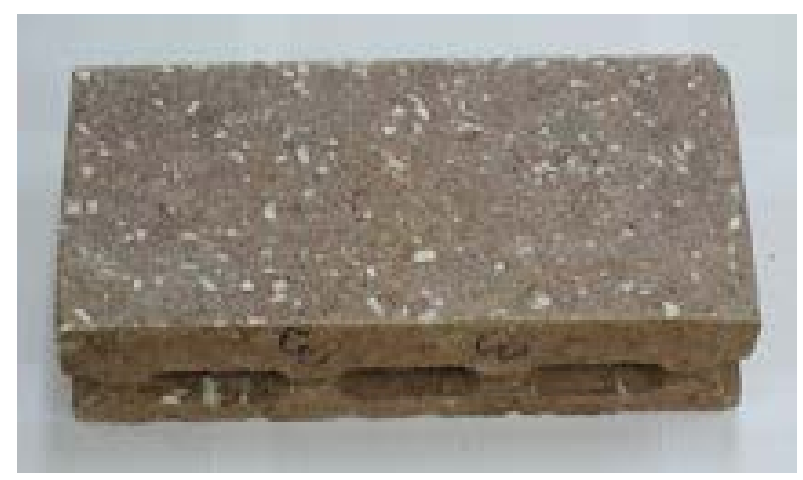

(c)

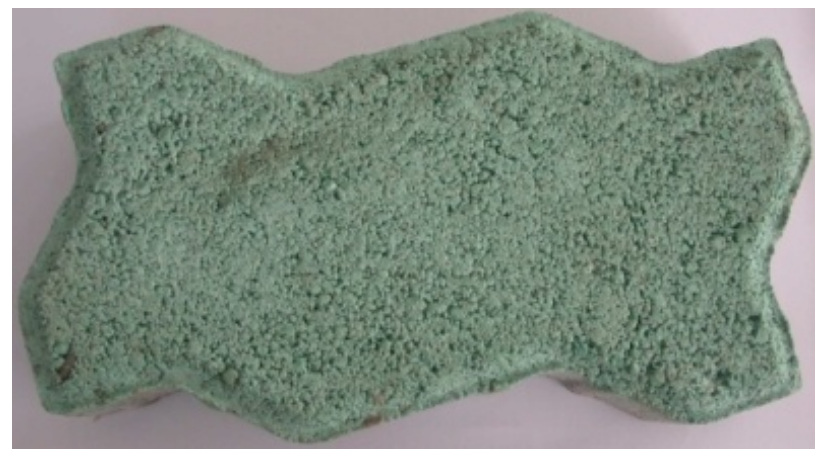

(d)

Figure 9 Applications of titania produced from sludge to (a) titania coating materials, (b) titania ceramic filter for air/water purification, (c) titania coated concrete brick and (d) pavement brick

\subsection{Pigment application of titania}

Titania from sludge has a high refractive index and an high reflectance. The characteristics can be applied to a pigment industry in paints, plastics, paper, inks, fibers and cosmetics. This material can be also used as an opacifier in glass and porcelain enamels, sunscreens and cement. As such, the application to pigment has a significant potential after modification of titania produced from sludge.

Figure 10 shows the application to paper preparation using titania produced from sludge to improve opacifying value. Flocculation using $\mathrm{TiCl}_{4}$ with printing paper mill wastewater was performed to generate titania. The titania from printing paper mill wastewater consisted of aggregated structures with round shape of dimension of 10-15 $\mathrm{nm}$ as a primary crystal growth, including various dopant materials such as carbon (4.3\%), magnesium (0.9\%), aluminium (1.9\%), silicon (1.7\%), sulphur $(0.7 \%)$ and calcium (3.8\%). The whitening of titania collected sludge can be improved by an alkaline hydrothermal method with sodium hydroxide. Therefore the application to pigment in preparing paper would be one of the major applications. 


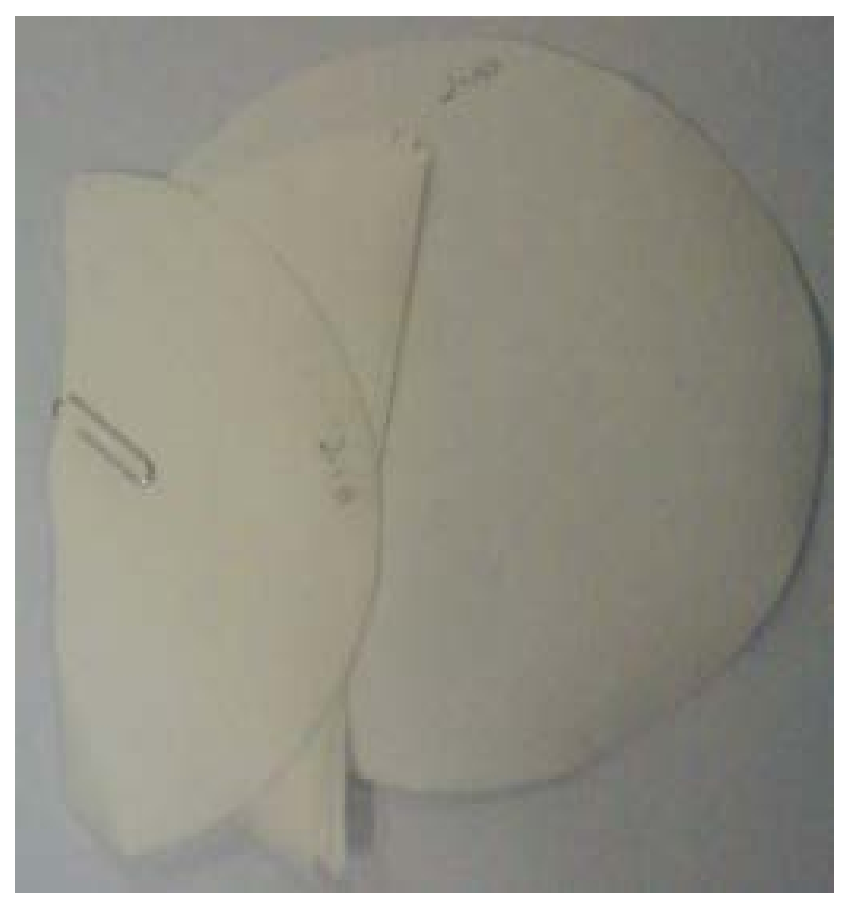

Figure 10 Application to paper using titania produced from sludge to improve opacifying value

\subsection{Application to nanostructured titania}

Titania nanotubes are expected to have some improved properties for photocatalytic applications compared with colloidal, nanoparticles and other forms $[29,30]$. The tubular structure, large surface area, high sedimentation rate are the main properties of titania nanotubes which make them more suitable to be utilized as photocatalysts for the degradation of organic pollutants [31,32]. Even though there are many vital reservations regarding the photocatalytic property of titanate nanotubes, few researchers persisted that the as-prepared sodium or hydrogen titanate nanotubes have enough potential to degrade the organic pollutants efficiently [32,33]. On the contrary, some researchers believed that neither of sodium or hydrogen titanate nanotubes can be used as a photocatalyst.

Several attempts to improve titania properties are still undergoing and different one dimensional nanostructures are being investigated [13,21]. The studies investigated the feasibility of using titania nanoparticles and titania nanotubes produced from DW, SW and WW flocculation as photocatalysts. 
The Ti-salt flocculated sludge produced from DW, SW and WW was calcined at $600{ }^{\circ} \mathrm{C}$ to produce titania. XRD results showed that the anatase titania structure was predominant for titania from different water sources. Titanate nanotubes were obtained when the nanoparticles from different water sources were hydrothermally treated with $10 \mathrm{~N} \mathrm{NaOH}$ solution at $130^{\circ} \mathrm{C}$ for $24 \mathrm{~h}$. Figure 11 shows SEM images of titania nanoparticles and titanate nanotubes produced from DW, SW and WW. The nanoparticles were nearly spherically shaped and having reasonably uniform size distribution. However, after hydrothermal treatment, the analyses confirmed the formation of nanotubes structures. It is believed that the titania nanoparticles undergo delaminating process due to the attack of excess sodium cations, to produce two-dimensional nanosheets. These nanosheets could grow at reaction temperature and curl-up into nanotubes due to high surface energy. These nanotubes were found to have approximate lengths of a few hundred nanometers and diameters around 10-50 nm. The structure phase, shape, crystallization and the photocatalytic activity were greatly affected by the calcination temperature and amount of sodium present in different samples.

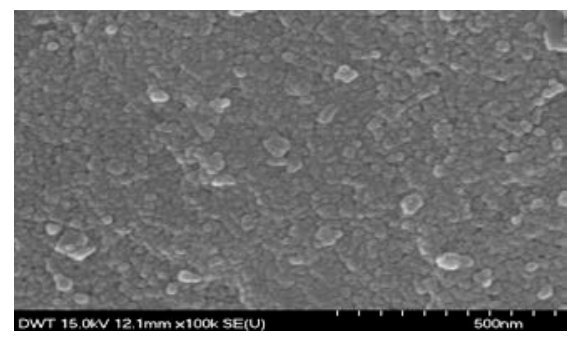

Titania nanoparticles from DW

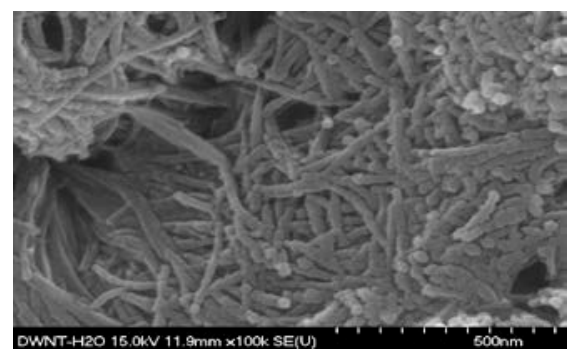

Titanate nanotubes from DW

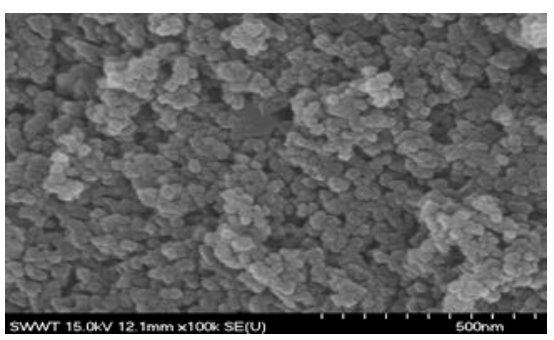

Titania nanoparticles from SW

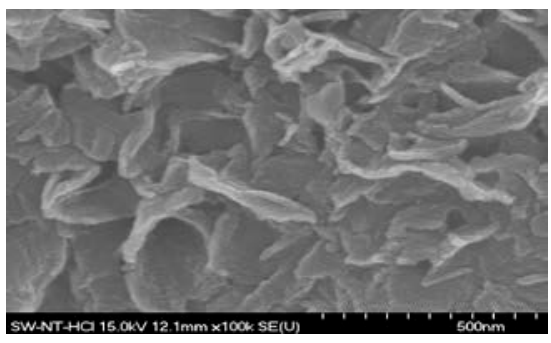

Titanate nanotubes from SW

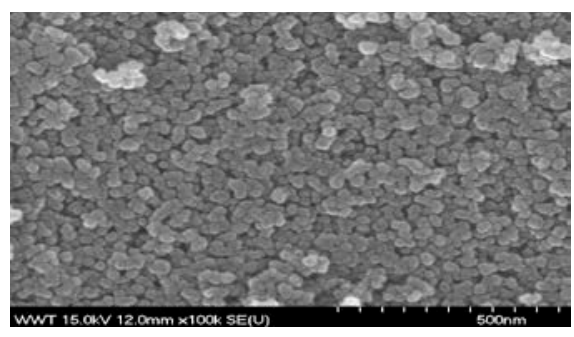

Titania nanoparticles from WW

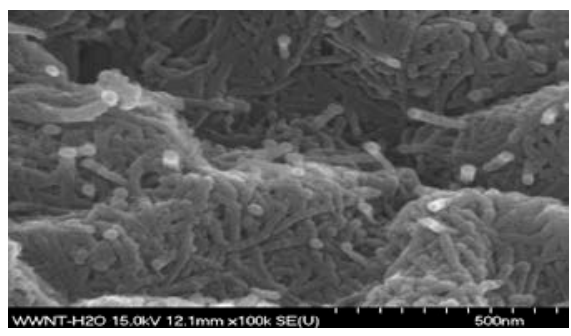

Titanate nanotubes from WW

Figure 11 Scanning electronic micrographs of titania nanoparticles and titanate nanotubes produced from drinking water, seawater and wastewater 


\section{Conclusions}

During flocculation sludge disposal is one of the most costly and environmentally problematic challenges of modern water treatment worldwide. In this review, we report a new process which could significantly lower the cost of waste disposal, protect the environment and public health and yield economically useful by-product. This work uses Ti-salt flocculation instead of aluminum and iron coagulants commonly used for flocculation. The Ti-based flocculation was effective in removing organic matter. The flocculated sludge was calcined at $600^{\circ} \mathrm{C}$ to produce functional photoreactive titania nanomaterials. The anatase titania nanomateirals from wastewater produced by $\mathrm{TiCl}_{4}$ flocculation with $6 \mathrm{~nm}$ size was found to be superior to commercial titania (P-25) in terms of photocatalytic activity and surface area. The titania was found to be mainly doped with C- and Patoms. The atomic percentage of the titania was $\mathrm{TiO}_{1.42} \mathrm{C}_{0.44} \mathrm{P}_{0.14}$.

Aquatic toxicity of the Ti-salt flocculation processes was investigated using $D$. magna and $V$. fischeri bioassays. Both results showed very low acute toxicity effect for $\mathrm{TiCl}_{4}$ coagulant and titania produced from different water sources. Pilot/full scale flocculation using $\mathrm{TiCl}_{4}$ to treat dye wastewater was investigated. The organic removal was similar to the one obtained from the commonly used coagulants but the settling of $\mathrm{TiCl}_{4}$ sludge was faster which made the subsequent separation process easier. The photocatalytic activity of titania from dye wastewater was comparable to that of commercial P-25 under UV light. According to the mass balance, 7\% of wastewater sludge mass can be made into valuable titania nanoparticles in the full scale feasibility test.

Three case studies of titania applications produced from Ti-salt flocculated sludge with polluted 
water were investigated in terms of a pigment, environment and construction material. The applications of titania to coating materials, ceramic filter for air/water purification, coated concrete brick and pavement brick were successfully carried out. The titania improved opacifying value for the application of paper as a pigment. Titanate nanotubes were obtained when the titania nanoparticles from sludge were hydrothermally treated with $\mathrm{NaOH}$ solution.

\section{Acknowledgements}

This work was supported by Priority Research Centers Program through the National Research Foundation of Korea (NRF) funded by the Ministry of Education, Science and Technology (20090094057) and the Center for Photonic Materials and Devices at Chonnam National University. This subject is supported by Korea Ministry of Environment as "Converging technology project". This was also funded by a CRC-CARE project.

\section{References}

[1]. L. Rizzo, V. Belgiorno, M. Gallo and S. Meriç, Desal., 176 (2005) 177.

[2]. J. DeWolfe, B. Dempsey, M. Taylor, J. W. Potter, Guidance manual for coagulant changeover; (American Water Works Association Press: Denver, 2003).

[3]. J.L. Stauber, T.M. Florence, C.M. Davies, M.S. Adams, S.J. Buchanan, J. Am. Water Works Assoc. 91 (2005) 84.

[4]. H.K. Shon, J.H. Kim et al. Methods for recovering organic·inorganic element-doped metal oxide from hydrolytic metal compound associated with contaminated water treatment. Patent identification number: PCT/KR2006/000201, 2006.

[5]. H.K. Shon, S. Vigneswaran, In S. Kim, J. Cho, G.J. Kim, J-.B. Kim and J-.H. Kim, Environ. Sci. Technol., 41, (2007) 1372. 
[6]. B.C. Lee, S. Kim, H.K. Shon, S. Vigneswaran, J.B. Kim, H.J. Park, J.-H. Kim, J. Nanopart. Res. 11 (2009) 2087.

[7]. H.K. Shon, S. Vigneswaran, J. Kandasamy, M.H. Zareie, J.B. Kim, D.L. Cho, J.-H. Kim, Sep. Sci. Technol. 44 (2009) 1525.

[8]. H.K. Shon, D.L. Cho, S.H. Na, J.B. Kim, H.J. Park, J.-H. Kim, J. Ind. Eng. Chem. 15 (2009) 476.

[9]. H.K. Shon, S. Vigneswaran, J. Kandasamy, J.B. Kim, H.J. Park, S.W. Choi, J.-H. Kim, J. Ind. Eng. Chem. 15 (2009) 719.

[10]. Y. Okour, I.E. Saliby, H.K. Shon, S. Vigneswaran, J.-H. Kim, J. Cho, I.S. Kim, Desalination 249 (2009) 53.

[11]. Y. Okour, H.K. Shon, I.E. Saliby, Water Sci. Technol. 59 (2009) 2463.

[12]. I. El Saliby, Y. Okour, H.K. Shon, S. Vigneswaran, J. Kandasamy, J.-H. Kim, J. Adv. Oxid. Technol. 12 (2009) 194.

[13]. Y. Okour, H.K. Shon, I. El Saliby, R. Naidu, J.B. Kim and J.H. Kim. Bioresource Techn., $101(2010) 1453$.

[14]. S. Na, H.K. Shon, J.B. Kim, H.J. Park, D.L. Cho, I. El Saliby and J.-H. Kim, J. Ind. Eng. Chem. 16 (2010) 96.

[15]. J.B. Kim, H.J. Park, H.K. Shon, D.L. Cho, G.J. Kim, S.W. Choi and J.H. Kim, J. Nanosci. Nanotech. 10 (2010) 3260.

[16]. H.K. Shon, S. Vigneswaran, Y. Okour, J.B. Kim, J.-H. Kim, In S. Kim and J. Cho, Desal. Wat. Treat., 15 (2010) 214.

[17]. I. El Saliby, H.K. Shon, Y.H. Okour, S. Vigneswaran, M. Senthilnanthanan and J. Kandasamy, J. Adv. Oxi. Technol. 13 (2010) 15.

[18]. H.K. Shon, S. Puntsho, Y. Okour, D.L. Cho, K.S. Kim, H.J. Li, S.H. Na, J.B. Kim and J.-H. Kim, J. Korean Ind. Eng. Chem. 19 (2008) 1.

[19]. H.K. Shon, Y. Okour, I. El Saliby, J. Park, D.-L. Cho, J.B. Kim, H.J. Park and J.-H. Kim, J. 
Korean Ind. Eng. Chem. 20 (2009) 241.

[20]. H.K. Shon, S. Phuntsho, J. Kadasamy, S. Vigneswaran, L.D. Nghiem, G.J. Kim, J.B. Kim and J.-H. Kim, Environmental Science \& Technology, 44 (2010), 5553-5557..

[21]. J.-H. Kim, Y. Okour, J.B. Kim, H.K. Shon, J. Nanosci. Nanotech. (2010) In press.

[22]. W.V. Upton and A.M. Buswell, Ind. Eng. Chem. 870 (1937).

[23]. E.P. Lokshin and M.L. Belikov. Russ. J. Appl. Chem., 76, (2003) 466.

[24]. M. Higarashi., W.F. Jardim, Catal. Today, 76 (2002) 201.

[25]. J.R. Payne and C.R. Phillips, Environ. Sci. Technol. 19 (1985) 569.

[26]. C. Minero, V. Maurino and E. Pelizzetti, Marine Chem. 58 (1997) 361.

[27]. G. Martinez, J. Maria, I.D. Riva, L. Canoira, J.F. Llamas, R. Alcantara and J. R. Gallego, App. Catal. B: Environmental 67 (2006) 279.

[28].L. Marion, P. Xavier, N. Nikolaus, D. Frank, and N. Reinhard, App. Catal. B: Environmental, 43 (2003) 205.

[29]. A. Ghicov, J.M. Macak, H. Tsuchiya, J. Kunze, V. Haeublein, L. Frey, P. Schmuki, Nano. Lett. 6 (2006) 1080.

[30]. J.M. Macak, M. Zlamal, J. Krysa, P. Schmuki, Small 3 (2007) 300.

[31]. X. Quan, S.G. Yang, X.L. Ruan, H.M. Zhao, Environ. Sci. Technol. 39 (2005) 3770.

[32]. S. Yang , Y. Liu, C. Sun , Applied Catalysis A: General 301 (2006) 284.

[33]. J. Li , W. Ma, C. Chen, J. Zhao, H. Zhu, X. Gaod, J. Mol. Catal. A: Chemical 261 (2007) 131. 